\title{
Hyperbaric Oxygen Treatment-From Mechanisms to Cognitive Improvement
}

\author{
Irit Gottfried ${ }^{1}$, Nofar Schottlender ${ }^{1,2}$ and Uri Ashery $1,2, *$ \\ 1 School of Neurobiology, Biochemistry and Biophysics, Life Sciences Faculty, Tel Aviv University, \\ Tel Aviv 6997801, Israel; iritgo@tauex.tau.ac.il (I.G.); schottlender@mail.tau.ac.il (N.S.) \\ 2 Sagol School of Neuroscience, Tel Aviv University, Tel Aviv 6997801, Israel \\ * Correspondence: uria@tauex.tau.ac.il; Tel.: +972-3-6409827
}

Citation: Gottfried, I.; Schottlender, N.; Ashery, U. Hyperbaric Oxygen Treatment-From Mechanisms to Cognitive Improvement. Biomolecules 2021, 11, 1520. https://doi.org/ 10.3390/biom 11101520

Academic Editor: Vladimir N. Uversky

Received: 14 September 2021 Accepted: 13 October 2021 Published: 15 October 2021

Publisher's Note: MDPI stays neutral with regard to jurisdictional claims in published maps and institutional affiliations.

Copyright: (C) 2021 by the authors. Licensee MDPI, Basel, Switzerland. This article is an open access article distributed under the terms and conditions of the Creative Commons Attribution (CC BY) license (https:// creativecommons.org/licenses/by/ $4.0 /)$.

\begin{abstract}
Hyperbaric oxygen treatment (HBOT) - the medical use of oxygen at environmental pressure greater than one atmosphere absolute-is a very effective therapy for several approved clinical situations, such as carbon monoxide intoxication, incurable diabetes or radiation-injury wounds, and smoke inhalation. In recent years, it has also been used to improve cognition, neurowellness, and quality of life following brain trauma and stroke. This opens new avenues for the elderly, including the treatment of neurological and neurodegenerative diseases and improvement of cognition and brain metabolism in cases of mild cognitive impairment. Alongside its integration into clinics, basic research studies have elucidated HBOT's mechanisms of action and its effects on cellular processes, transcription factors, mitochondrial function, oxidative stress, and inflammation. Therefore, HBOT is becoming a major player in 21 st century research and clinical treatments. The following review will discuss the basic mechanisms of HBOT, and its effects on cellular processes, cognition, and brain disorders.
\end{abstract}

Keywords: hyperbaric oxygen treatment (HBOT); cognition; brain disorders; neuroprotection; neuroinflammation; Alzheimer's disease

\section{Hyperbaric Oxygen Treatment (HBOT): The Concept}

HBOT - the medical administration of $100 \%$ oxygen at environmental pressure greater than one atmosphere absolute (ATA) — is used clinically for a wide range of medical conditions. One of HBOT's main mechanisms of action is elevation of the partial pressure of oxygen in the blood and tissues as compared to simple oxygen supplementation [1,2]. This allows five to ten times more oxygen to enter the blood plasma and to reach tissues suffering from low oxygen supply (following, e.g., brain injury, stroke, or vascular dysfunction). Therefore, it is not surprising that HBOT has been used for over 50 years for wounds (nonhealing diabetic foot ulcers), air embolisms or decompression sickness, burned tissue repair, carbon monoxide intoxication, peripheral arterial occlusive disease, smoke inhalation, radiation injury, and promoting recovery from serious illness [3-10]. Nevertheless, today, there are only 13 FDA-approved HBOTs [11]; however, in parallel, there are a growing number of "off-label" uses, which have not been cleared by the FDA, such as treatment for stroke patients or patients suffering from Alzheimer's disease (AD) [12,13], and even treatment of COVID-19 patients, which have shown very promising results [14-19]. Further clinical trials that are currently in progress, and additional basic scientific studies aimed at understanding HBOT's mechanisms of action, will most probably expand the use of HBOT to other areas.

\section{Cognitive Improvement \\ 2.1. Cognitive Improvement Following Brain Injuries}

Although the use of HBOT in cases of brain-related disorders is pending FDA approval, there are numerous studies showing improved cognitive assessment following 
treatment for several brain injuries [20]. For example, post-stroke patients suffer from reduced cognitive performance, and in particular, memory difficulties. HBOT for stroke patients at late chronic stages has shown significant improvements in all memory measures. These clinical improvements are well-correlated with improvements in brain metabolism, mainly in temporal areas. High oxygen (92\%) alone was also shown to positively affect the working memory of individuals with intellectual and developmental disabilities, at least in the short-term [21]. Similar improvement was seen in a large cohort of post-stroke patients who underwent $40 \mathrm{HBOT}$ sessions (2 ATA), leading to significant neurological and cognitive improvements, even at the late chronic phase after stroke [22,23]. Mechanistically, in preclinical studies, HBOT has been suggested to reduce oxidative stress, inflammation, and neural apoptosis, thereby improving functional recovery from stroke [24]. It was also suggested that HBOT in rats suffering from ischemic stroke stimulates the expression of trophic factor and neurogenesis, and the mobilization of bone marrow stem cells to the ischemic area, which can enhance cell repair [25]. In addition, HBOT elevates cerebral blood flow (CBF), associated with restoration of physical abilities and cognitive functions [26,27]. The improvement in cognition and executive functions, as well as in physical abilities, gait, sleep, and quality of life in these stroke patients continued for up to three months after the last treatment, which was the follow-up period in that study [27]. These encouraging results suggest the occurrence of long-term changes, lasting the order of months. Similarly, in patients with mild traumatic brain injury (TBI), HBOT improved hippocampal $\mathrm{CBF}$ [28] and facilitated recovery during the rehabilitation phase [29]. Moreover, growing evidence suggests that HBOT can induce neuroplasticity and improve cognitive function in patients suffering from chronic neurocognitive impairment due to TBI, stroke, and anoxic brain damage [22,23,30-32]. These changes were associated with the induction of cerebral angiogenesis, increased CBF and volume, and improved cerebral white and gray microstructures [33].

Other teams have investigated whether HBOT can improve brain function and cognition in neurodegenerative diseases such as AD and vascular dementia (VD), and if HBOT can also affect healthy people or improve cognitive decline in the elderly who are suffering from cognitive impairments.

\subsection{Cognitive Improvement Following HBOT in $A D$ and $V D$}

Recent human studies have shown that HBOT can improve cognitive functions in patients with mild cognitive impairment (MCI), AD, and VD [13,20,34-38], and ameliorate the reduced brain metabolism in MCI and AD [34,35]. Similarly, cerebrovascular disease patients showed improvement in motor and cognitive performance compared to a control group following HBOT [38]. Interestingly, improvements in cognitive function assessed by Mini-Mental State Exam (MMSE) and Mini-Cog test were reported in AD patients even one month after the end of the last HBOT, and for up to three months in amnestic MCI patients. In addition, HBOT ameliorated the reduced brain glucose metabolism in some of the AD and amnestic MCI patients [34]. These are very promising results, because they suggest that even with severe cognitive deterioration in progressive neurodegenerative brain disorders, relatively short-duration HBOT (40 min once a day for 20 days) can improve conditions for one to three months. In a more severe case of $\mathrm{AD}$, a longer treatment of eight weeks (1.15 ATA) reversed the patient's symptomatic decline and PET scan showed an increase in brain metabolism [35]. Nevertheless, the current belief is that HBOT cannot revert severe cases with major neuron loss and therefore should be considered mainly at early disease stages, when only minimal cognitive deficiency is detected. It should be noted that the elevation of pressure by itself was also suggested to regulate $\mathrm{AD} \mathrm{[39].}$ However, further research in this direction should explore the exact effect. A larger group of VD patients who received 12 weeks of HBOT (2 ATA) showed improvement in MMSE scores and elevated serum humanin levels [36]. Humanin is a unique human mitochondrion-derived peptide that has neuroprotective effects [40-42] and, together with findings of increased brain metabolism, this suggests an important role for improving 
mitochondrial function as part of HBOT's mechanism of action. As HBOT use in the clinic is considered to be safe and well-tolerated, it should be considered and recommended as an alternative therapeutic approach for AD and VD [37], as well as in early stages of MCI. Hence, HBOT improves several aspects of brain activity including an improvement in cerebral blood flow, brain metabolism, and brain microstructure, and this leads to improvement in cognitive functions and physical functions, sleep, and gait leading to an overall improved performance (Figure 1). Nevertheless, it is also clear that although the effects of HBOT last, in some studies, for several months, when treating patients with progressive neurodegenerative diseases such as $\mathrm{AD}$, maintenance $\mathrm{HBO}$ treatments will probably be needed.

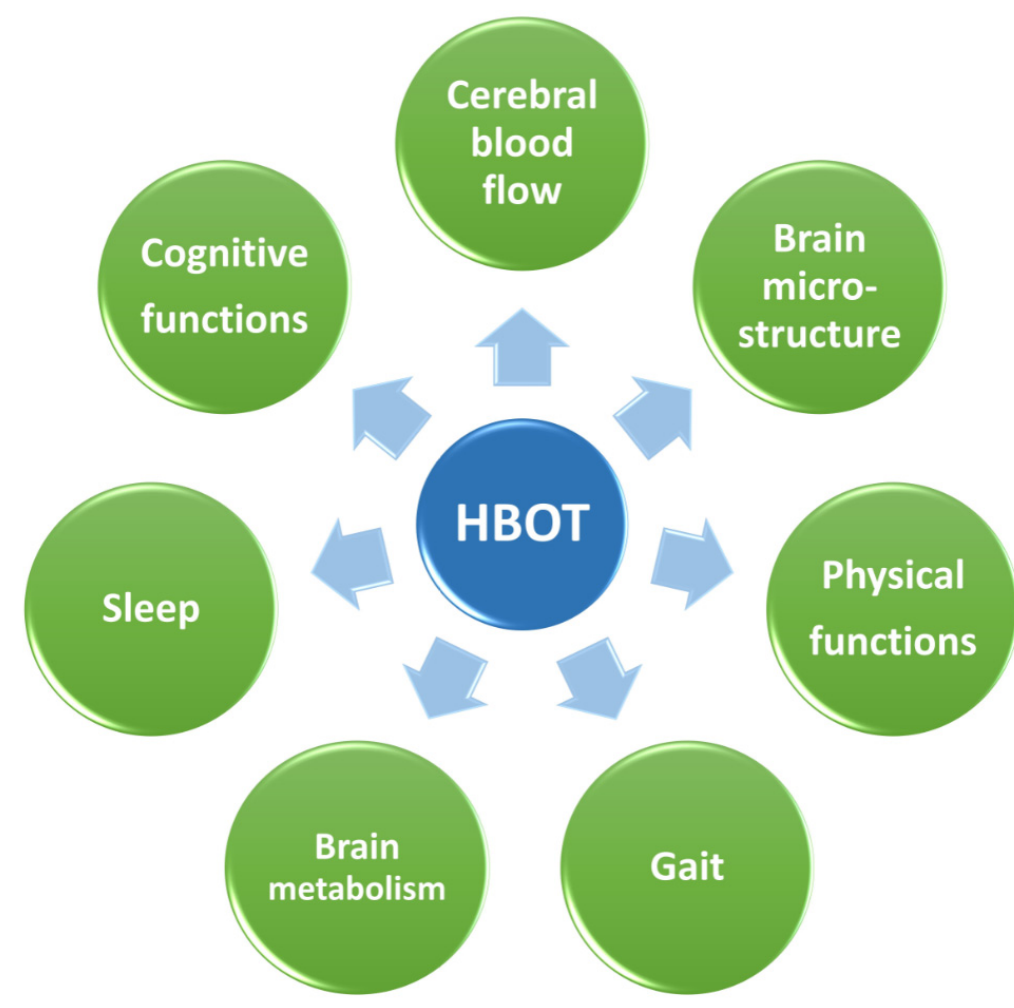

Figure 1. HBOT improves brain function. HBOT has been shown to improve cerebral blood flow, brain metabolism, and brain microstructure, leading to improved cognitive functions, physical functions, sleep, and gait.

\subsection{Cognitive Improvement in Healthy Individuals}

Over the last few decades, several studies have examined the possible contribution of HBOT to cognitive performance in both young and elderly populations. In one of the first studies examining the effects of HBOT on the elderly [43], it was found to improve cognitive function in elderly patients with cognitive deficits. In a more recent study with a cohort of healthy young adults, HBOT increased spatial working memory and memory quotient, and this was correlated with changes in regional homogeneity as measured by resting-state functional MRI [44]. In another prospective study, double-blind randomized healthy volunteers were asked to perform a cognitive task, a motor task and a simultaneous cognitive-motor task (multitasking) while in a functional HBO chamber. Compared to the performance under normobaric conditions, single cognitive and motor task, and multitasking performance scores were significantly enhanced by the $\mathrm{HBO}$ environment, supporting the hypothesis that oxygen is a rate-limiting factor for brain activity [45]. These results were further validated by two recent studies that examined the effects of HBOT on healthy young [46] and old [47] adults. In these studies, HBOT resulted in an improved learning curve and higher resilience to interference of episodic memory in the healthy young adults [46], and induced cognitive enhancements in healthy aging adults, which 
were associated with regional improvement in CBF [47]. Similarly, in a recent paper, a group of elderly patients with memory loss at baseline to HBOT showed improved cognitive performances following 60 daily HBOT sessions (2 ATA) and this was associated with an increase in CBF [48]. Interestingly, when HBOT was applied for a short time (only 15 consecutive days), there was no improvement in cognitive impairment in the elderly [49], suggesting that a longer treatment is necessary. Indeed, current protocols are extending the treatment to two to three months (40-60 daily sessions, 5 days per week, 2-3 ATA) and promise to yield more significant and long-lasting effects [12].

In summary, it is clear that the $\mathrm{HBO}$ environment, in and of itself, improves cognitive performance, and that this can be attributed directly to the elevated oxygen levels, suggesting that oxygen is a rate-limiting factor for brain activity [45]. However, repeated exposure to HBOT for longer periods of time is needed to achieve long-lasting effects that lead to changes in vascular, neuronal, and cellular activity, as detailed in Figure 2 [12].

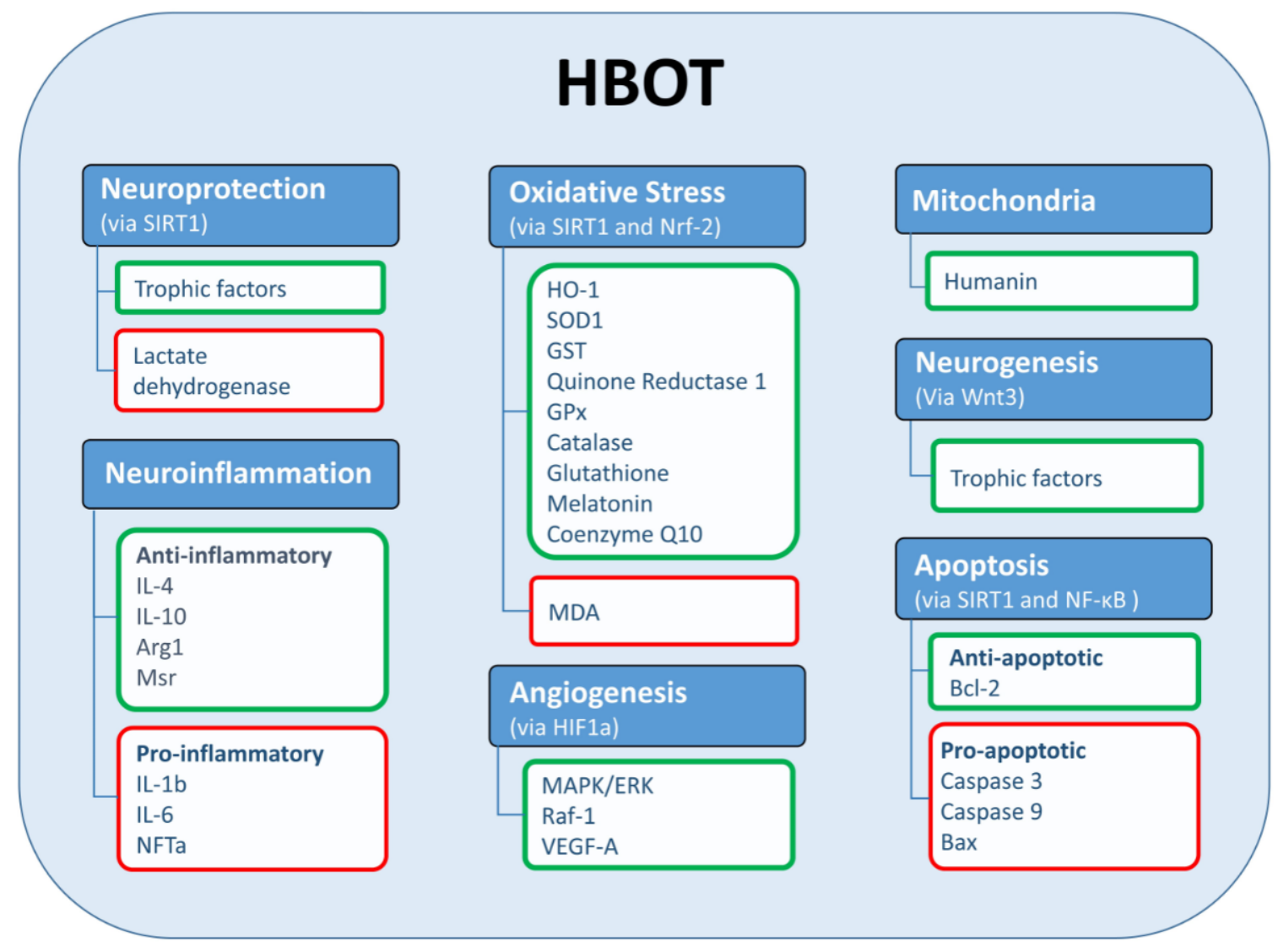

Figure 2. HBOT affects multiple cellular and molecular pathways. HBOT affects several molecular and cellular pathways that are important for cellular and neuronal recovery including neuroprotection via SIRT1, oxidative stress via SIRT1 and Nrf-2, apoptosis via SIRT1, neurogenesis via Wnt3. Green frames represent proteins and processes that are upregulated; red frames represent proteins and processes that are downregulated. Abbreviations: nuclear factor erythroid 2-related factor 2 (Nrf-2), nuclear factor kappa B (NF-kB), Hypoxia-Inducible Factor 1-alpha (HIF1a), heme oxygenase 1 (HO-1), superoxide dismutase 1 (SOD1), malondialdehyde (MDA), B-cell lymphoma 2 (Bcl2), Bcl-2-associated X protein (Bax), vascular endothelial growth factor (VEGF-A), Glutathione-S-transferases (GST), Glutathione Peroxidase (GPx), tumor necrosis factor alpha (TNFa), Wnt Family Member 3 (Wnt3).

\section{Mechanistic Explanation for the Effects of HBOT on Cognition}

What are the cellular and molecular pathways that contribute to the long-term neuron, function- and cognition-enhancing effects of HBOT? A series of studies using animal models for brain injuries and brain diseases showed an improvement in the animals cognitive performance and provided a mechanistic understanding of some of HBOT's 
effects. Not surprisingly, these effects are not mediated by a single pathway, but were found to be mediated by several pathways, including inhibition of apoptosis, improvement of mitochondrial function, stem cell proliferation, enhancement of antioxidant defense activity, reduction in neuroinflammation, and neuroprotection (Figure 2). The "normobaric oxygen paradox" or "hyperoxic-hypoxic paradox" has been suggested to play a key role in HBOT's effects [12,50-52]. It is based on the fact that during HBOT sessions, oxygen level is increased from 21 to $100 \%$ (or less in some cases) and at the end of each treatment, oxygen level is reduced back to $21 \%$. Such fluctuations activate several factors: elevation of oxygen can activate nuclear factor erythroid 2-related factor 2 (Nrf-2), while the reduction to $21 \%$ can be interpreted as a hypoxic signal and activate Hypoxia-Inducible Factor 1-alpha (HIF1a) [50,51]. HIF1a belongs to a family of proteins that are involved in angiogenesis and vascular remodeling, erythropoiesis, glycolysis, iron transport, and survival [53-55]. $\mathrm{Nrf} 2$ is involved in several cellular defense mechanisms, and it mediates the repair and degradation of damaged proteins $[51,55,56]$, and activates the antioxidant pathways and the detoxification of endogenous and exogenous products [57]. Under high hyperoxia, nuclear factor kappa B (NF-kB), which is usually activated under oxidative stress and inflammation, is also activated [51], and mediates inflammatory and immune responses. NF- $\mathrm{kB}$ is also involved in synaptic plasticity and in the antiapoptotic pathway by activating Bcl-2 [58]. Some of these effects are discussed below. It should be noted that the optimal conditions for achieving best results from the "Hyperoxic-Hypoxic Paradox" require additional research in the coming years.

\subsection{Mitochondrial Function}

Mitochondria consume roughly 85 to $90 \%$ of the oxygen that we breathe and are the major source of ATP production. It is therefore likely that the main molecular target of HBOT is the mitochondrion. As already noted, humanin, a neuroprotective mitochondrionderived peptide in humans, was elevated in VD patients following HBOT [36], suggesting a major role for mitochondrial activity in HBOT's mechanisms of action. Recent studies have suggested the therapy's direct effects on neurons were mediated by mitochondrial transfer from cell to cell. HBOT was shown to facilitate the transfer of mitochondria from astrocytes to neuronal cells, making the latter more resilient to neuroinflammation [59]. This neuroglial crosstalk may facilitate recovery and explain some of the mechanisms induced by HBOT [50]. In TBI rats, HBOT for $4 \mathrm{~h}$ (1.5 ATA) led to an increase in ATP levels and neuron survival, both of which were associated with improved cognitive recovery [60]. Furthermore, in a rat model for AD, HBOT reduced mitochondria-mediated apoptosis signaling by increasing Bcl-2, which is anti-apoptotic, and decreasing Bcl-2-associated $\mathrm{X}$ protein (Bax), which is pro-apoptotic [61].

\subsection{Neurogenesis and Angiogenesis}

An additional avenue for cognitive improvement might be stem cell proliferation. Stem cell proliferation has been documented on various occasions following HBOT [62-64], and evidence for neuronal cell proliferation has emerged in the last two decades. In an early study, HBOT for hypoxic ischemic neonatal rats promoted neurogenesis of endogenous neuronal stem cells, as measured by an increase in both 5-bromo-2'-deoxyuridine (BrdU) and doublecortin, in the subventricular zone (SVZ) and the hippocampal dentate gyrus (DG) —an area involved in spatial navigation [65]. Accordingly, HBOT improved spatial learning and memory abilities in rats with TBI [66]. This was associated with an increase in hippocampal neuronal activity.

These results were further supported by another study in which HBOT induced neuronal cell proliferation, as revealed by an increase in nestin and BrdU in the hippocampal DG area [67] and elevation of Wnt-3 and nestin in the SVZ [68]. In a study aimed at examining the mechanistic contribution of HBOT to recovery from TBI, it was found that HBOT increases neuronal stem cell proliferation and migration to the lesion area, as well as the levels of vascular endothelial growth factor (VEGF) and its receptor VEGFR-2, Raf-1, 
Mitogen-activated protein kinase (MEK1/2), and phospho-extracellular signal-regulated kinase (ERK) 1/2 protein [69]. Accordingly, it was suggested that HBOT promotes neuronal stem cell proliferation and possibly angiogenesis through VEGF/ERK signaling [69]. Moreover, in a rat model for VD, HBOT also stimulated neurogenesis in the piriform cortex and improved blood supply [70]. HBOT was also shown to enhance mobilization of bone marrow stem cells to an ischemic area and the release of trophic factors that can promote brain and neuronal recovery and enhance neurogenesis [25]. Interestingly, in patients with delayed encephalopathy after acute carbon monoxide poisoning, HBOT mobilized, circulating stem cells in the peripheral blood, which was associated with improved cognition [71]. In a TBI rat model, HBOT stimulated angiogenesis as evidenced by a higher number of BrdU- and VEGF-positive cells, and an increase in the number of BrdU- and NeuNpositive cells, suggesting enhanced neurogenesis [72]. These findings provide support for improvement of human brain cognition associated with changes in cerebral angiogenesis and neuronal growth and proliferation improving CBF and brain activity [33]. Indeed, a recent study showed that HBOT improves blood flow in an AD mouse model by mitigating the blood vessel constriction that occurs in these AD mice under the regular course of the disease but without HBOT. This was associated with an improved performance of the AD mice [48]. Moreover, in elderly patients with significant memory loss at baseline, HBOT increased CBF and improved cognitive performance [48]. It would be interesting to examine whether HBOT also restores neurogenesis in neurodegenerative diseases such as $\mathrm{AD}$, and whether it will affect neurogenesis and angiogenesis [73] in wild-type mice and healthy humans.

\subsection{Neuroinflammation}

Another important effect of HBOT in several brain dysfunctions is reduced neuroinflammation. TBI is usually associated with increased inflammation, apoptosis and gliosis, neuronal cell death, and cognitive and motor dysfunction. In a TBI rat model, HBOT was shown to reduce neuroinflammation and increase levels of the anti-inflammatory cytokine interleukin (IL)-10; these changes were associated with improvements in cognitive deficit [72]. In an AD mouse model, HBOT reversed hypoxia and ameliorated brain pathology, and improved the animals' behavioral performance [74,75]. This improvement was also associated with a reduction in proinflammatory cytokines such as IL-1b, IL-6, and tumor necrosis factor alpha (TNF $\alpha$ ), and an increase in anti-inflammatory cytokines such as IL-4 and IL-10, leading to reduced neuroinflammation. HBOT also significantly improved recovery from sepsis following cecal ligation and puncture; the treatment was associated with a reduction in the inflammatory response, including decreased expression of TNF $\alpha$, IL-6, and IL-10 $[17,76]$. Changes in cytokines following exposure to oxygen have also been reported in humans. A low-intensity exercise program in combination with exposure to mild hyperoxia ( $30 \%$ ) elevates the proinflammatory IL-6 that contributes to host defense during infection and tissue, while at both mild ( $30 \%$ oxygen) and high hyperoxic state ( $100 \%$ oxygen), the anti-inflammatory cytokine IL-10 was elevated significantly [52]. In a rat model for $\mathrm{MCI}$, HBOT had a protective effect on early cognitive dysfunction that was mediated by ERK. These animals performed better in the Morris water maze, and showed less apoptosis and better hippocampal cell morphology [77]. In a rat model for AD that was induced by injections of amyloid $\beta$ peptide into the hippocampus, HBOT improved animal behavior, and reduced neuronal damage, astrocyte activation, and dendritic spine loss. This was associated with a reduction in hippocampal p38 mitogen-activated protein kinase (MAPK) phosphorylation [78], which occurs in the early stage of the disease and is associated with increased neuroinflammation, cytoskeletal remodeling, and tau phosphorylation $[79,80]$. These papers suggest that the MAPK/ERK pathways, which are involved in cell proliferation and plasticity, are also a target for HBOT. 


\subsection{Neuroprotective, Antioxidant, and Antiapoptotic Activities}

HBO preconditioning induced tolerance to cerebral ischemia [81]. This was mediated by an increase in SIRT1, a class III histone deacetylase, which has been suggested to be involved in neuroprotection [82]. The neuroprotective effect of preconditioning HBOT was associated with a reduction in lactate dehydrogenase and was attenuated by a reduction in SIRT1 activity or expression by either the SIRT1 inhibitor EX527 or SIRT1 knockdown. Interestingly, the neuroprotective effect was mimicked by resveratrol, a SIRT1 activator. Changes in SIRT1 level were also associated with elevation in B-cell lymphoma 2 (Bcl-2) expression and a decrease in cleaved caspase 3 level, suggesting that some of the effects might be mediated via inhibition of apoptosis [82]. Moreover, expression of SIRT1 in the brain was associated with increased expression of the nuclear factor erythroid 2-related factor 2 (Nrf-2), heme oxygenase 1 (HO-1), and superoxide dismutase 1 (SOD1), whereas the level of malondialdehyde (MDA) decreased, supporting the notion that HBOT enhances the antioxidant defense pathway, thereby assisting in neuroprotection [83]. Indeed, HBO preconditioning increased the expression of SIRT1, Nrf-2, and HO-1 and ameliorated memory dysfunction in additional models of cognitive decline [84], and SIRT1 was also shown to play a role in recovery after middle cerebral artery occlusion in rats. Therefore, this might serve as the mechanism for HBOT's effects in cases of acute ischemic stroke [85]. A combination of HBOT and Ginkgo biloba extract following induction of toxicity with amyloid $\beta$ (A $\beta$ fragments) demonstrated enhanced SOD and glutathione levels, while levels of MDA and Bax, and activity of caspases 9 and 3 were reduced in rat hippocampal tissue, suggesting both antioxidant and antiapoptotic activity $[61,86]$. In a mouse model for mild TBI, HBOT improved learning abilities and prevented astrocyte activation and neuronal loss, suggesting a neuroprotective effect [87]. Additional involvement in apoptotic pathways was demonstrated in an $\mathrm{AD}$ rat model that showed improved cognitive and memory abilities following HBOT, which were associated with NF- $\mathrm{kB}$ pathway activation and reduced hippocampal neuron loss [88]. Further animal model studies may reveal additional mechanisms underlying the effects of HBOT, thus facilitating the development of more efficient HBOT protocols. Taken together, HBOT has a multifaceted neuroprotective effect on the brain that involves the immune, neuronal and vascular systems, leading to enhancement and recovery of cognitive performance.

\section{HBOT-The Next Leap}

HBOT has been used for centuries to treat a variety of symptoms and syndromes, and in recent years, it has been shown to improve many brain disorders. Nevertheless, it is still not fully established clinically, and additional basic research and clinical trials are necessary. Notably, in recent years, numerous such clinical trials have been supported by the NIH. Over 230 clinical trials examining HBOT have been reported (https:/ clinicaltrials.gov/, accessed on 4 September 2021). Of these, 50 clinical trials are examining the effects of HBOT on brain-related injuries and disorders. Current and future clinical trials will provide additional validated information for a wider range of disorders, while basic research will expand our mechanistic understanding and help optimize treatment conditions by allowing for more accurate determinations of treatment length, frequency of treatments, and the exact protocol. This will reduce cost, time, and complications. Overall, HBOT is becoming a central player in the 21st century healthcare system with the ability to improve both personal performance and cognition.

Author Contributions: All authors were involved in writing-original draft preparation, review, and editing. All authors have read and agreed to the published version of the manuscript.

Funding: N.S. is supported by a Scholarship from the Tel Aviv University Center for Combatting Pandemics. U.A. was supported by The Aufzien Family Center for the Prevention and Treatment of Parkinson's Disease at Tel Aviv University.

Conflicts of Interest: The authors declare no conflict of interest. 


\section{References}

1. Calvert, J.W.; Cahill, J.; Zhang, J.H. Hyperbaric oxygen and cerebral physiology. Neurol. Res. 2007, 29, 132-141. [CrossRef]

2. Jones, M.W.; Brett, K.; Han, N.; Wyatt, H.A. Hyperbaric Physics; StatPearls Publishing: Treasure Island, FL, USA, 2019.

3. Glik, J.; Cholewka, A.; Stanek, A.; Englisz, B.; Sieroń, K.; Mikuś-Zagórska, K.; Knefel, G.; Nowak, M.; Kawecki, M. Thermal imaging and planimetry evaluation of the results of chronic wounds treatment with hyperbaric oxygen therapy. Adv. Clin. Exp. Med. 2019, 28, 229-236. [CrossRef]

4. Kasprzyk-Kucewicz, T.; Cholewka, A.; Englisz-Jurgielewicz, B.; Mucha, R.; Relich, M.; Kawecki, M.; Sieroń, K.; Onak, P.; Stanek, A. Thermal effects of topical hyperbaric oxygen therapy in hard-to-heal wounds-A pilot study. Int. J. Environ. Res. Public Health 2021, 18, 6737. [CrossRef]

5. Stanek, A.; Gebala-Prajsnar, K.; Pasek, J.; Prajsnar, G.; Berszakiewicz, A.; Sieron, A.; Cholewka, A.; Zabrze, I. Selected physical medicine interventions in the treatment of diabetic foot syndrome. Acta Angiol. 2015, 21, 140-145. [CrossRef]

6. Lin, P.-Y.; Sung, P.-H.; Chung, S.-Y.; Hsu, S.-L.; Chung, W.-J.; Sheu, J.-J.; Hsueh, S.-K.; Chen, K.-H.; Wu, R.-W.; Yip, H.-K. Clinical Medicine Hyperbaric Oxygen Therapy Enhanced Circulating Levels of Endothelial Progenitor Cells and Angiogenesis Biomarkers, Blood Flow, in Ischemic Areas in Patients with Peripheral Arterial Occlusive Disease. J. Clin. Med. 2018, 7, 548. [CrossRef]

7. Carturan, D.; Boussuges, A.; Vanuxem, P.; Bar-Hen, A.; Burnet, H.; Gardette, B. Ascent rate, age, maximal oxygen uptake, adiposity, and circulating venous bubbles after diving. J. Appl. Physiol. 2002, 93, 1349-1356. [CrossRef]

8. Edwards, M.; Singh, M.; Selesny, S.; Cooper, J.S. Hyperbaric Treatment of Thermal Burns; StatPearls Publishing: Treasure Island, FL, USA, 2021.

9. Cooper, J.S.; Hanley, M.E. Hyperbaric Treatment of Radiation Proctitis; StatPearls Publishing: Treasure Island, FL, USA, 2021.

10. Hanley, M.E.; Manna, B. Hyperbaric Treatment of Diabetic Foot Ulcer; StatPearls Publishing: Treasure Island, FL, USA, 2021.

11. Hyperbaric Oxygen Therapy: Get the Facts I FDA. Available online: https://www.fda.gov/consumers/consumer-updates/ hyperbaric-oxygen-therapy-get-facts (accessed on 6 October 2021).

12. Kamat, S.M.; Mendelsohn, A.R.; Larrick, J.W. Rejuvenation through Oxygen, More or Less. Rejuvenation Res. 2021, $24,158-163$. [CrossRef]

13. Somaa, F. A Review of the Application of Hyperbaric Oxygen Therapy in Alzheimer's Disease. J. Alzheimer's Dis. 2021, 81, 1361-1367. [CrossRef] [PubMed]

14. Thibodeaux, K.; Speyrer, M.; Raza, A.; Yaakov, R.; Serena, T.E. Hyperbaric oxygen therapy in preventing mechanical ventilation in COVID-19 patients: A retrospective case series. J. Wound Care 2020, 29, S4-S8. [CrossRef] [PubMed]

15. Abu El Hawa, A.A.; Charipova, K.; Bekeny, J.C.; Johnson-Arbor, K.K. The evolving use of hyperbaric oxygen therapy during the COVID-19 pandemic. J. Wound Care 2021, 30, S8-S11. [CrossRef] [PubMed]

16. Paganini, M.; Bosco, G.; Perozzo, F.A.G.; Kohlscheen, E.; Sonda, R.; Bassetto, F.; Garetto, G.; Camporesi, E.M.; Thom, S.R. The Role of Hyperbaric Oxygen Treatment for COVID-19: A Review. In Advances in Experimental Medicine and Biology; Springer: Cham, Switzerland, 2021; Volume 1289, pp. 27-35.

17. De Maio, A.; Hightower, L.E. COVID-19, acute respiratory distress syndrome (ARDS), and hyperbaric oxygen therapy (HBOT): What is the link? Cell Stress Chaperones 2020, 25, 717-720. [CrossRef]

18. Guo, D.; Pan, S.; Wang, M.M.; Guo, Y. Hyperbaric oxygen therapy may be effective to improve hypoxemia in patients with severe COVID-2019 pneumonia: Two case reports. Undersea Hyperb. Med. 2020, 47, 181-187. [CrossRef] [PubMed]

19. Boet, S.; Etherington, C.; Djaiani, G.; Tricco, A.C.; Sikora, L.; Katznelson, R. Efficacy and safety of hyperbaric oxygen treatment in SARS-CoV-2 (COVID-19) pneumonia: A systematic review. Diving Hyperb. Med. 2021, 51, 271-281. [CrossRef] [PubMed]

20. Marcinkowska, A.B.; Mankowska, N.D.; Kot, J.; Winklewski, P.J. Impact of Hyperbaric Oxygen Therapy on Cognitive Functions: A Systematic Review. Neuropsychol. Rev. 2021. [CrossRef]

21. Kim, H.-S.; Choi, M.-H.; Baek, J.-H.; Park, S.-J.; Lee, J.-C.; Jeong, U.-H.; Kim, S.-P.; Kim, H.-J.; Choi, Y.; Lim, D.-W.; et al. Effects of $92 \%$ oxygen administration on cognitive performance and physiological changes of intellectually and developmentally disabled people. J. Physiol. Anthropol. 2015, 34, 3. [CrossRef] [PubMed]

22. Hadanny, A.; Rittblat, M.; Bitterman, M.; May-Raz, I.; Suzin, G.; Boussi-Gross, R.; Zemel, Y.; Bechor, Y.; Catalogna, M.; Efrati, S. Hyperbaric oxygen therapy improves neurocognitive functions of post-stroke patients-a retrospective analysis. Restor. Neurol. Neurosci. 2020, 38, 93-107. [CrossRef] [PubMed]

23. Efrati, S.; Fishlev, G.; Bechor, Y.; Volkov, O.; Bergan, J.; Kliakhandler, K.; Kamiager, I.; Gal, N.; Friedman, M.; Ben-Jacob, E.; et al. Hyperbaric oxygen induces late neuroplasticity in post stroke patients-Randomized, prospective trial. PLoS ONE 2013, 8, e53716. [CrossRef] [PubMed]

24. Cozene, B.; Sadanandan, N.; Gonzales-Portillo, B.; Saft, M.; Cho, J.; Park, Y.J.; Borlongan, C.V. An extra breath of fresh air: Hyperbaric oxygenation as a stroke therapeutic. Biomolecules 2020, 10, 1279. [CrossRef]

25. Lee, Y.S.; Chio, C.C.; Chang, C.P.; Wang, L.C.; Chiang, P.M.; Niu, K.C.; Tsai, K.J. Long course hyperbaric oxygen stimulates neurogenesis and attenuates inflammation after ischemic stroke. Mediat. Inflamm. 2013, 2013, 512978. [CrossRef] [PubMed]

26. Chen, L.; Li, F.; Gu, D. Hyperbaric oxygen therapy for cerebral blood flow and electroencephalogram in patients with acute cerebral infarction: Choice for therapeutic occasion. Neural Regen. Res. 2007, 2, 171-174. [CrossRef]

27. Rosario, E.R.; Kaplan, S.E.; Khonsari, S.; Vazquez, G.; Solanki, N.; Lane, M.; Brownell, H.; Rosenberg, S.S. The Effect of Hyperbaric Oxygen Therapy on Functional Impairments Caused by Ischemic Stroke. Neurol. Res. Int. 2018, 2018, 3172679. [CrossRef] [PubMed] 
28. Ma, J.; Hong, G.; Ha, E.; Hong, H.; Kim, J.; Joo, Y.; Yoon, S.; Lyoo, I.K.; Kim, J. Hippocampal cerebral blood flow increased following low-pressure hyperbaric oxygenation in firefighters with mild traumatic brain injury and emotional distress. Neurol. Sci. 2021, 42, 4131-4138. [CrossRef] [PubMed]

29. Skiba, M.; Rękas-Dudziak, A.; Bekała, A.; Płotek, W. Late application of hyperbaric oxygen therapy during the rehabilitation of a patient with severe cognitive impairment after a traumatic brain injury. Clin. Case Rep. 2021, 9, 960-965. [CrossRef] [PubMed]

30. Tal, S.; Hadanny, A.; Berkovitz, N.; Sasson, E.; Ben-Jacob, E.; Efrati, S. Hyperbaric oxygen may induce angiogenesis in patients suffering from prolonged post-concussion syndrome due to traumatic brain injury. Restor. Neurol. Neurosci. 2015, 33, 943-951. [CrossRef] [PubMed]

31. Boussi-Gross, R.; Golan, H.; Fishlev, G.; Bechor, Y.; Volkov, O.; Bergan, J.; Friedman, M.; Hoofien, D.; Shlamkovitch, N.; Ben-Jacob, E.; et al. Hyperbaric oxygen therapy can improve post concussion syndrome years after mild traumatic brain injury-Randomized prospective trial. PLoS ONE 2013, 8, e79995. [CrossRef]

32. Harch, P.; Andrews, S.; Rowe, C.; Lischka, J.; Townsend, M.; Yu, Q.; Mercante, D. Hyperbaric oxygen therapy for mild traumatic brain injury persistent postconcussion syndrome: A randomized controlled trial. Med. Gas Res. 2020, 10, 8-20. [CrossRef] [PubMed]

33. Tal, S.; Hadanny, A.; Sasson, E.; Suzin, G.; Efrati, S. Hyperbaric Oxygen Therapy Can Induce Angiogenesis and Regeneration of Nerve Fibers in Traumatic Brain Injury Patients. Front. Hum. Neurosci. 2017, 11, 508. [CrossRef] [PubMed]

34. Chen, J.; Zhang, F.; Zhao, L.; Cheng, C.; Zhong, R.; Dong, C.; Le, W. Hyperbaric oxygen ameliorates cognitive impairment in patients with Alzheimer's disease and amnestic mild cognitive impairment. Alzheimer's Dement. 2020, 6, e12030. [CrossRef]

35. Harch, P.G.; Fogarty, E.F. Hyperbaric oxygen therapy for Alzheimer's dementia with positron emission tomography imaging: A case report. Med. Gas Res. 2018, 8, 181-184. [CrossRef]

36. Xu, Y.; Wang, Q.; Qu, Z.; Yang, J.; Zhang, X.; Zhao, Y. Protective Effect of Hyperbaric Oxygen Therapy on Cognitive Function in Patients with Vascular Dementia. Cell Transpl. 2019, 28, 1071-1075. [CrossRef]

37. You, Q.; Li, L.; Xiong, S.-Q.; Yan, Y.-F.; Li, D.; Yan, N.-N.; Chen, H.-P.; Liu, Y.-P. Meta-Analysis on the Efficacy and Safety of Hyperbaric Oxygen as Adjunctive Therapy for Vascular Dementia. Front. Aging Neurosci. 2019, 11, 86. [CrossRef]

38. Vila, J.F.; Balcarce, P.E.; Abiusi, G.R.; Domínguez, R.O.; Pisarello, J.B. Improvement in motor and cognitive impairment after hyperbaric oxygen therapy in a selected group of patients with cerebrovascular disease: A prospective single-blind controlled trial. Undersea Hyperb. Med. 2005, 32, 341-349.

39. Denis, P.A. Alzheimer's disease: A gas model. The NADPH oxidase-Nitric Oxide system as an antibubble biomachinery. Med. Hypotheses 2013, 81, 976-987. [CrossRef]

40. Zárate, S.C.; Traetta, M.E.; Codagnone, M.G.; Seilicovich, A.; Reinés, A.G. Humanin, a mitochondrial-derived peptide released by astrocytes, prevents synapse loss in hippocampal neurons. Front. Aging Neurosci. 2019, 11, 123. [CrossRef] [PubMed]

41. Hazafa, A.; Batool, A.; Ahmad, S.; Amjad, M.; Chaudhry, S.N.; Asad, J.; Ghuman, H.F.; Khan, H.M.; Naeem, M.; Ghani, U. Humanin: A mitochondrial-derived peptide in the treatment of apoptosis-related diseases. Life Sci. 2021, 264, 118679. [CrossRef]

42. Hashimoto, Y.; Ito, Y.; Niikura, T.; Shao, Z.; Hata, M.; Oyama, F.; Nishimoto, I. Mechanisms of neuroprotection by a novel rescue factor humanin from swedish mutant amyloid precursor protein. Biochem. Biophys. Res. Commun. 2001, 283, 460-468. [CrossRef] [PubMed]

43. Jacobs, E.A.; Winter, P.M.; Alvis, H.J.; Small, S.M. Hyperoxygenation Effect on Cognitive Functioning in the Aged. N. Engl. J. Med. 1969, 281, 753-757. [CrossRef]

44. Yu, R.; Wang, B.; Li, S.; Wang, J.; Zhou, F.; Chu, S.; He, X.; Wen, X.; Ni, X.; Liu, L.; et al. Cognitive enhancement of healthy young adults with hyperbaric oxygen: A preliminary resting-state fMRI study. Clin. Neurophysiol. 2015, 126, 2058-2067. [CrossRef] [PubMed]

45. Vadas, D.; Kalichman, L.; Hadanny, A.; Efrati, S. Hyperbaric Oxygen Environment Can Enhance Brain Activity and Multitasking Performance. Front. Integr. Neurosci. 2017, 11, 25. [CrossRef]

46. Suzin, G.; Frolinger, T.H.; Yogev, D.; Hadanny, A.; Catalogna, M.; Rassovsky, Y.; Efrati, S. Oxygen: The rate-limiting factor for episodic memory performance, even in healthy young individuals. Biomolecules 2020, 10, 1328. [CrossRef]

47. Hadanny, A.; Malka, D.K.; Gil, S.; Rahav, B.G.; Merav, C.; Kobi, D.; Yafit, H.; Ramzia, A.H.; Efrat, S.; Gregory, F.; et al. Cognitive enhancement of healthy older adults using hyperbaric oxygen: A randomized controlled trial. Aging 2020, 12, 13740-13761. [CrossRef]

48. Shapira, R.; Gdalyahu, A.; Gottfried, I.; Sasson, E.; Hadanny, A.; Efrati, S.; Blinder, P.; Ashery, U. Hyperbaric oxygen therapy alleviates vascular dysfunction and amyloid burden in an Alzheimer's disease mouse model and in elderly patients. Aging 2021, 13, 20935-20961. [CrossRef]

49. Raskin, A.; Gershon, S.; Crook, T.H.; Sathananthan, G.; Ferris, S. The effects of hyperbaric and normobaric oxygen on cognitive impairment in the elderly. Arch. Gen. Psychiatry 1978, 35, 50-56. [CrossRef] [PubMed]

50. Hadanny, A.; Efrati, S. The hyperoxic-hypoxic paradox. Biomolecules 2020, 10, 958. [CrossRef] [PubMed]

51. Fratantonio, D.; Virgili, F.; Zucchi, A.; Lambrechts, K.; Latronico, T.; Lafère, P.; Germonpré, P.; Balestra, C. Increasing oxygen partial pressures induce a distinct transcriptional response in human pbmc: A pilot study on the "normobaric oxygen paradox". Int. J. Mol. Sci. 2021, 22, 458. [CrossRef] [PubMed] 
52. Balestra, C.; Lambrechts, K.; Mrakic-Sposta, S.; Vezzoli, A.; Levenez, M.; Germonpré, P.; Virgili, F.; Bosco, G.; Lafère, P. Hypoxic and Hyperoxic Breathing as a Complement to Low-Intensity Physical Exercise Programs: A Proof-of-Principle Study. Int. J. Mol. Sci. 2021, 22, 9600. [CrossRef] [PubMed]

53. Van Vliet, T.; Casciaro, F.; Demaria, M. To breathe or not to breathe: Understanding how oxygen sensing contributes to age-related phenotypes. Ageing Res. Rev. 2021, 67, 101267. [CrossRef] [PubMed]

54. Greer, S.N.; Metcalf, J.L.; Wang, Y.; Ohh, M. The updated biology of hypoxia-inducible factor. EMBO J. 2012, 31, 2448-2460. [CrossRef] [PubMed]

55. Fratantonio, D.; Cimino, F.; Speciale, A.; Virgili, F. Need (more than) two to Tango: Multiple tools to adapt to changes in oxygen availability. BioFactors 2018, 44, 207-218. [CrossRef]

56. Cimino, F.; Speciale, A.; Anwar, S.; Canali, R.; Ricciardi, E.; Virgili, F.; Trombetta, D.; Saija, A. Anthocyanins protect human endothelial cells from mild hyperoxia damage through modulation of Nrf2 pathway. Genes Nutr. 2013, 8, 391-399. [CrossRef]

57. Tonelli, C.; Chio, I.I.C.; Tuveson, D.A. Transcriptional Regulation by Nrf2. Antioxid. Redox Signal. 2018, 29, 1727-1745. [CrossRef]

58. Mattson, M.P.; Meffert, M.K. Roles for NF-кB in nerve cell survival, plasticity, and disease. Cell Death Differ. 2006, 13, 852-860. [CrossRef] [PubMed]

59. Lippert, T.; Borlongan, C.V. Prophylactic treatment of hyperbaric oxygen treatment mitigates inflammatory response via mitochondria transfer. CNS Neurosci. Ther. 2019, 25, 815-823. [CrossRef] [PubMed]

60. Zhou, Z.; Daugherty, W.P.; Sun, D.; Levasseur, J.E.; Altememi, N.; Hamm, R.J.; Rockswold, G.L.; Bullock, M.R. Protection of mitochondrial function and improvement in cognitive recovery in rats treated with hyperbaric oxygen following lateral fluid-percussion injury. J. Neurosurg. 2007, 106, 687-694. [CrossRef] [PubMed]

61. Tian, X.; Zhang, L.; Wang, J.; Dai, J.; Shen, S.; Yang, L.; Huang, P. The protective effect of hyperbaric oxygen and Ginkgo biloba extract on A $325-35$-induced oxidative stress and neuronal apoptosis in rats. Behav. Brain Res. 2013, 242, 1-8. [CrossRef]

62. Thom, S.R.; Milovanova, T.N.; Yang, M.; Bhopale, V.M.; Sorokina, E.M.; Uzun, G.; Malay, D.S.; Troiano, M.A.; Hardy, K.R.; Lambert, D.S.; et al. Vasculogenic stem cell mobilization and wound recruitment in diabetic patients: Increased cell number and intracellular regulatory protein content associated with hyperbaric oxygen therapy. Wound Repair Regen. 2011, 19, 149-161. [CrossRef]

63. Goldstein, L.J.; Gallagher, K.A.; Bauer, S.M.; Bauer, R.J.; Baireddy, V.; Liu, Z.-J.; Buerk, D.G.; Thom, S.R.; Velazquez, O.C. Endothelial Progenitor Cell Release into Circulation Is Triggered by Hyperoxia-Induced Increases in Bone Marrow Nitric Oxide. Stem Cells 2006, 24, 2309-2318. [CrossRef]

64. Milovanova, T.N.; Bhopale, V.M.; Sorokina, E.M.; Moore, J.S.; Hunt, T.K.; Hauer-Jensen, M.; Velazquez, O.C.; Thom, S.R. Hyperbaric oxygen stimulates vasculogenic stem cell growth and differentiation in vivo. J. Appl. Physiol. 2009, 106, 711-728. [CrossRef]

65. Yang, Y.J.; Wang, X.L.; Yu, X.H.; Wang, X.; Xie, M.; Liu, C.T. Hyperbaric oxygen induces endogenous neural stem cells to proliferate and differentiate in hypoxic-ischemic brain damage in neonatal rats. Undersea Hyperb. Med. $2008,35,113-129$.

66. Liu, S.; Shen, G.; Deng, S.; Wang, X.; Wu, Q.; Guo, A. Hyperbaric oxygen therapy improves cognitive functioning after brain injury. Neural Regen. Res. 2013, 8, 3334-3343. [CrossRef]

67. Wei, L.; Wang, J.; Cao, Y.; Ren, Q.; Zhao, L.; Li, X.; Wang, J. Hyperbaric oxygenation promotes neural stem cell proliferation and protects the learning and memory ability in neonatal hypoxic-ischemic brain damage. Int. J. Clin. Exp. Pathol. 2015, 8, 1752-1759.

68. Wang, X.L.; Yang, Y.J.; Xie, M.; Yu, X.H.; Liu, C.T.; Wang, X. Proliferation of neural stem cells correlates with Wnt-3 protein in hypoxic-ischemic neonate rats after hyperbaric oxygen therapy. Neuroreport 2007, 18, 1753-1756. [CrossRef]

69. Yang, Y.; Wei, H.; Zhou, X.; Zhang, F.; Wang, C. Hyperbaric oxygen promotes neural stem cell proliferation by activating vascular endothelial growth factor/extracellular signal-regulated kinase signaling after traumatic brain injury. Neuroreport 2017, 28 , 1232-1238. [CrossRef] [PubMed]

70. Zhang, T.; Yang, Q.-W.W.; Wang, S.-N.N.; Wang, J.-Z.Z.; Wang, Q.; Wang, Y.; Luo, Y.-J.J. Hyperbaric oxygen therapy improves neurogenesis and brain blood supply in piriform cortex in rats with vascular dementia. Brain Inj. 2010, 24, 1350-1357. [CrossRef] [PubMed]

71. Zhang, L.; Sun, Q.; Xin, Q.; Qin, J.; Zhang, L.; Wu, D.; Gao, G.; Xia, Y. Hyperbaric oxygen therapy mobilized circulating stem cells and improved delayed encephalopathy after acute carbon monoxide poisoning with up-regulation of brain-derived neurotrophic factor. Am. J. Emerg. Med. 2021, 42, 95-100. [CrossRef] [PubMed]

72. Lin, K.-C.C.; Niu, K.-C.C.; Tsai, K.-J.J.; Kuo, J.-R.R.; Wang, L.-C.C.; Chio, C.-C.C.; Chang, C.-P.P. Attenuating inflammation but stimulating both angiogenesis and neurogenesis using hyperbaric oxygen in rats with traumatic brain injury. J. Trauma Acute Care Surg. 2012, 72, 650-659. [CrossRef] [PubMed]

73. Buckley, C.J.; Cooper, J.S. Hyperbaric Affects on Angiogenesis; StatPearls Publishing: Treasure Island, FL, USA, 2021.

74. Shapira, R.; Solomon, B.; Efrati, S.; Frenkel, D.; Ashery, U. Hyperbaric oxygen therapy ameliorates pathophysiology of 3xTg-AD mouse model by attenuating neuroinflammation. Neurobiol. Aging 2018, 62, 105-119. [CrossRef]

75. Shapira, R.; Efrati, S.; Ashery, U. Hyperbaric oxygen therapy as a new treatment approach for Alzheimer's disease. Neural Regen. Res. 2018, 13. [CrossRef]

76. Halbach, J.L.; Prieto, J.M.; Wang, A.W.; Hawisher, D.; Cauvi, D.M.; Reyes, T.; Okerblom, J.; Ramirez-Sanchez, I.; Villarreal, F.; Patel, H.H.; et al. Early hyperbaric oxygen therapy improves survival in a model of severe sepsis. Am. J. Physiol. Regul. Integr. Comp. Physiol. 2019, 317, R160-R168. [CrossRef] 
77. Lin, Y.; Lin, X.; Zheng, X.; Liu, F.; Ye, C.; Huang, L.; Zhou, Q.; Chen, T.; Lin, L. Hyperbaric oxygen therapy cognitive function in a rat model of mild cognitive impairment via ERK signaling. Ann. Cardiothorac. Surg. 2020, 9, 3472-3480. [CrossRef]

78. Zhao, B.; Pan, Y.; Wang, Z.; Xu, H.; Song, X. Hyperbaric oxygen pretreatment improves cognition and reduces hippocampal damage via p38 mitogen-activated protein kinase in a rat model. Yonsei Med. J. 2017, 58, 131-138. [CrossRef]

79. Corrêa, S.A.L.; Eales, K.L. The Role of p38 MAPK and Its Substrates in Neuronal Plasticity and Neurodegenerative Disease. J. Signal Transduct. 2012, 2012, 1-12. [CrossRef]

80. Sun, A.; Liu, M.; Nguyen, X.V.; Bing, G. p38 MAP kinase is activated at early stages in Alzheimer's disease brain. Exp. Neurol. 2003, 183, 394-405. [CrossRef]

81. Gamdzyk, M.; Małek, M.; Bratek, E.; Koks, A.; Kaminski, K.; Ziembowicz, A.; Salinska, E. Hyperbaric oxygen and hyperbaric air preconditioning induces ischemic tolerance to transient forebrain ischemia in the gerbil. Brain Res. 2016, 1648, 257-265. [CrossRef]

82. Yan, W.; Fang, Z.; Yang, Q.; Dong, H.; Lu, Y.; Lei, C.; Xiong, L. SirT1 mediates hyperbaric oxygen preconditioning-induced ischemic tolerance in rat brain. J. Cereb. Blood Flow Metab. 2013, 33, 396-406. [CrossRef] [PubMed]

83. Xue, F.; Huang, J.W.; Ding, P.Y.; Zang, H.G.; Kou, Z.J.; Li, T.; Fan, J.; Peng, Z.W.; Yan, W.J. Nrf2/antioxidant defense pathway is involved in the neuroprotective effects of Sirt1 against focal cerebral ischemia in rats after hyperbaric oxygen preconditioning. Behav. Brain Res. 2016, 309, 1-8. [CrossRef] [PubMed]

84. Hong-qiang, H.; Mang-qiao, S.; Fen, X.; Shan-shan, L.; Hui-juan, C.; Wu-gang, H.; Wen-jun, Y.; Zheng-wu, P. Sirt1 mediates improvement of isoflurane-induced memory impairment following hyperbaric oxygen preconditioning in middle-aged mice. Physiol. Behav. 2018, 195, 1-8. [CrossRef]

85. Hu, Q.; Manaenko, A.; Bian, H.; Guo, Z.; Huang, J.L.; Guo, Z.N.; Yang, P.; Tang, J.; Zhang, J.H. Hyperbaric Oxygen Reduces Infarction Volume and Hemorrhagic Transformation Through ATP/NAD+/Sirt1 Pathway in Hyperglycemic Middle Cerebral Artery Occlusion Rats. Stroke 2017, 48, 1655-1664. [CrossRef]

86. Tian, X.; Wang, J.; Dai, J.; Yang, L.; Zhang, L.; Shen, S.; Huang, P. Hyperbaric Oxygen and Ginkgo Biloba Extract Inhibit A $325-35-i n d u c e d$ Toxicity and Oxidative Stress in vivo: A Potential Role in Alzheimer's Disease. Int. J. Neurosci. 2012, 122, 563-569. [CrossRef]

87. Baratz-Goldstein, R.; Toussia-Cohen, S.; Elpaz, A.; Rubovitch, V.; Pick, C.G. Immediate and delayed hyperbaric oxygen therapy as a neuroprotective treatment for traumatic brain injury in mice. Mol. Cell. Neurosci. 2017, 83, 74-82. [CrossRef] [PubMed]

88. Zhang, L.D.; Ma, L.; Zhang, L.; Dai, J.G.; Chang, L.G.; Huang, P.L.; Tian, X.Q. Hyperbaric oxygen and ginkgo biloba extract ameliorate cognitive and memory impairment via nuclear factor Kappa-B pathway in rat model of alzheimer's disease. Chin. Med. J. 2015, 128, 3088-3093. [CrossRef] [PubMed] 